\title{
How fast does the Grim Reaper walk? Receiver operating characteristics curve analysis in healthy men aged 70 and over
}

\author{
(c) (1) (8)
}

Fiona F Stanaway research fellow ${ }^{1}$, Danijela Gnjidic research fellow ${ }^{234}$, Fiona M Blyth deputy director, Concord Health and Ageing in Men Project ${ }^{245}$, David G Le Couteur professor of geriatric medicine ${ }^{246}$, Vasi Naganathan staff specialist, associate professor ${ }^{24}$, Louise Waite staff specialist ${ }^{24}$, Markus J Seibel professor of endocrinology ${ }^{6}$, David J Handelsman director, professor ${ }^{26}$, Philip N Sambrook professor ${ }^{27}$, Robert G Cumming professor of geriatric medicine and epidemiology ${ }^{124}$

${ }^{1}$ Sydney School of Public Health, University of Sydney, Sydney, Australia; ${ }^{2}$ Sydney Medical School, University of Sydney, Sydney, Australia; ${ }^{3}$ Department of Clinical Pharmacology and Department of Aged Care, Royal North Shore Hospital, Sydney, Australia; ${ }^{4}$ Centre for Education and Research on Ageing, Concord Hospital, Sydney, Australia; ${ }^{5}$ Sax Institute, Sydney, Australia; ${ }^{6}$ ANZAC Research Institute, Concord Hospital, Sydney, Australia; ${ }^{7}$ Kolling Institute of Medical Research, Institute of Bone and Joint Research, Royal North Shore Hospital, Sydney, Australia

\begin{abstract}
Objective To determine the speed at which the Grim Reaper (or Death) walks.

Design Population based prospective study.

Setting Older community dwelling men living in Sydney, Australia.

Participants 1705 men aged 70 or more participating in CHAMP (Concord Health and Ageing in Men Project).

Main outcome measures Walking speed $(\mathrm{m} / \mathrm{s})$ and mortality. Receiver operating characteristics curve analysis was used to calculate the area under the curve for walking speed and determine the walking speed of the Grim Reaper. The optimal walking speed was estimated using the Youden index (sensitivity+specificity-1), a common summary measure of the receiver operating characteristics curve, and represents the maximum potential effectiveness of a marker.

Results The mean walking speed was 0.88 (range 0.15-1.60) m/s. The highest Youden index (0.293) was observed at a walking speed of 0.82 $\mathrm{m} / \mathrm{s}$ (2 miles (about $3 \mathrm{~km}$ ) per hour), corresponding to a sensitivity of $63 \%$ and a specificity of $70 \%$ for mortality. Survival analysis showed that older men who walked faster than $0.82 \mathrm{~m} / \mathrm{s}$ were 1.23 times less likely to die (95\% confidence interval 1.10 to 1.37 ) than those who walked slower $(P=0.0003)$. A sensitivity of 1.0 was obtained when a walking speed of $1.36 \mathrm{~m} / \mathrm{s}$ (3 miles (about $5 \mathrm{~km}$ ) per hour) or greater was used,
\end{abstract}

indicating that no men with walking speeds of $1.36 \mathrm{~m} / \mathrm{s}$ or greater had contact with Death.

Conclusion The Grim Reaper's preferred walking speed is $0.82 \mathrm{~m} / \mathrm{s}$ (2 miles (about $3 \mathrm{~km}$ ) per hour) under working conditions. As none of the men in the study with walking speeds of $1.36 \mathrm{~m} / \mathrm{s}$ ( 3 miles (about $5 \mathrm{~km}$ ) per hour) or greater had contact with Death, this seems to be the Grim Reaper's most likely maximum speed; for those wishing to avoid their allotted fate, this would be the advised walking speed.

\section{Introduction}

The Grim Reaper, the personification of death, is a well known mythological and literary figure. ${ }^{1-4}$ Reported characteristics include a black cloak with cowl, a scythe, and cachexia. High quality scientific research linking the Grim Reaper to mortality has been scarce, despite extensive anecdotes.

Walking speed is a commonly used objective measure of physical capability in older people, predicting survival in several cohort studies. ${ }^{5-7}$ A recent meta-analysis found that being in the lowest fourth of walking speed compared with the highest was associated with a threefold increased risk of mortality. ${ }^{8}$ Moreover, the association between slow walking speed and mortality seems consistent across several ethnic groups and shows a dose-response relation. ${ }^{8}$ Although the association 
between walking speed and mortality has been well documented, the plausible biological relation between the two remains unclear.

We assessed whether the relation between slow walking speed and mortality results from the increased likelihood of being caught by Death. By assessing this relation using receiver operating characteristics curve analysis, we hypothesised we would be able to determine the walking speed of the Grim Reaper-information of importance to public health.

\section{Methods}

We analysed data from the Concord Health and Ageing in Men Project (CHAMP), a cohort study of men aged 70 and over living in several inner city suburbs of Sydney, Australia. ${ }^{9}$ Participants were recruited from the electoral roll, which, as voting is compulsory in Australia, provides a representative population sample. As "living" in the study area was a criterion for entry to the study, we were unable to obtain Death's participation in clinic assessments. In addition, as far as we are aware Death is currently not listed on the Australian electoral roll.

Men were recruited from January 2005 to June 2007 and baseline assessments carried out at the first clinic visit. The only exclusion criterion was living in an aged care facility.

Walking speed was measured at usual pace. ${ }^{10}{ }^{11}$ Trained staff used a stopwatch to record the time taken by the men to walk $6 \mathrm{~m}$. The fastest time from two trials was used. Walking speeds were adjusted for height based on the definition of frailty used in the Cardiovascular Health Study. ${ }^{11}$

The men were followed-up by telephone at four-monthly intervals from the baseline assessment, and at clinic visits at two and five years, which enabled survival data to be updated. For both the baseline and follow-up visits, the men completed a questionnaire at home before coming to the clinic at Concord Hospital. Men who were not contactable by phone were sent letters every four months, or if unavailable a nominated contact was telephoned. If men withdrew from the study but agreed to passive follow-up, we ascertained any deaths through the New South Wales registry of births, deaths, and marriages. Follow-up times varied between men (mean 59.3 months). Follow-up began at the baseline assessment and ended on the date of death or the end of the study period. For withdrawals, the end date was the date at which we contacted the death registry.

\section{Statistical analyses}

Analysis was done using SAS version 9.2.We used receiver operating characteristics curve analysis (Sigmaplot program, version 11.0, Systat Software) to calculate the area under the curve for walking speed and to determine the optimal cut-off value for avoiding contact with Death. On the basis of our hypothesis, we took this optimal cut-off for walking speed to be the best estimation of the Grim Reaper's pace. The area under the curve describes the test's overall performance and can be used to compare different tests. A value of 1 indicates perfect discrimination, whereas a value of 0.5 indicates discrimination no better than chance.

We also calculated sensitivity and specificity. The optimal cut-off point was obtained by using the Youden index (sensitivity+specificity-1), without adjusting for covariates. This index, a common summary measure of the receiver operating characteristics curve, represents the maximum potential effectiveness of a marker. ${ }^{12}$ Statistical significance was set at less than 0.05 . We also estimated the walking speed providing a sensitivity of 1.0 (a "negative" test result being a speed above the cut-off) as this cut-off would indicate the speed at which no men had contact with Death and therefore the maximum ambulatory speed of the Grim Reaper. This maximum speed might be used in particular instances where people are attempting to outrun Death and avoid their allotted fate. Cox regression analysis was also carried out to estimate the hazard ratio (95\% confidence intervals) for mortality for men with walking speeds above and below that estimated for the Grim Reaper. The walking speed was also tested as a continuous variable.

\section{Results}

Of 2815 eligible men contacted, 1511 (53.7\%) participated in the study. An additional 194 men living in the study area heard about the study (from friends or the local media) and were recruited before receiving an invitation letter, giving a final sample of 1705 . As the CHAMP study area has a high proportion of immigrants, only $49.8 \%$ of men in the CHAMP study were born in Australia and $19.6 \%$ in Italy. Other main countries of birth were Great Britain (4.6\%), Greece (3.9\%), and China $(2.7 \%)$. The men have been followed for a mean of 59.3 months. Walking speed at baseline was not available in 77 men, mostly through inability to complete the test. A total of 266 deaths occurred during follow-up. The mean walking speed was 0.88 (range $0.15-1.60) \mathrm{m} / \mathrm{s}$. The figure $\Downarrow$ shows the receiver operating characteristics analysis. The highest Youden index (0.293) was observed at a walking speed of $0.82 \mathrm{~m} / \mathrm{s}$ ( 2 miles (about $3 \mathrm{~km}$ ) per hour), which corresponded to a sensitivity of $63 \%$ and a specificity of $70 \%$. Cox regression analysis showed that older men with a walking speed above $0.82 \mathrm{~m} / \mathrm{s}$ were 1.23 times less likely to die (95\% confidence interval 1.10 to 1.37 ) than those who had a slower walking speed $(\mathrm{P}=0.0003)$. For every one unit $(\mathrm{m} / \mathrm{s})$ increase in walking speed, the hazard ratio for increased mortality was 2.77 (95\% confidence interval 2.08 to 3.68; $\mathrm{P}<0.001)$. Moreover, a sensitivity of 1.0 was obtained when a walking speed of $1.36 \mathrm{~m} / \mathrm{s}$ ( 3 miles (about $5 \mathrm{~km}$ ) per hour) or greater was used, indicating that no men with walking speeds of $1.36 \mathrm{~m} / \mathrm{s}$ or greater had contact with Death.

\section{Discussion}

Based on receiver operating characteristics analysis and estimation of the Youden index, a walking speed of $0.82 \mathrm{~m} / \mathrm{s}$ ( 2 miles (about $3 \mathrm{~km}$ ) per hour) was most predictive of mortality. Therefore, we predict that this is the likely speed at which the Grim Reaper prefers to ambulate under working conditions. Older men who walked at speeds greater than $0.82 \mathrm{~m} / \mathrm{s}$ were 1.23 times less likely to encounter Death. In addition, no men walking at speeds of $1.36 \mathrm{~m} / \mathrm{s}$ ( 3 miles (about $5 \mathrm{~km}$ ) per hour) or above were caught by Death $(\mathrm{n}=22,1.4 \%)$. This supports our hypothesis that faster speeds are protective against mortality because fast walkers can maintain a safe distance from the Grim Reaper. Interestingly, the predicted walking speed of Death estimated in the present study is virtually identical to the gait speed $(0.80 \mathrm{~m} / \mathrm{s})$ associated with median life expectancy at most ages and for both sexes in a recent meta-analysis of gait speed and mortality using data from diverse populations. ${ }^{8}$ This indicates that the preferred walking speed of the Grim Reaper while collecting souls is relatively constant irrespective of people's geographical location, sex, or ethnic background.

\section{Strengths and limitations of the study}

To our knowledge this is the first paper to estimate the walking speed of the Grim Reaper, which has clear importance for public 
health. Strengths of this study include the large representative sample of older men from a variety of cultural backgrounds, enabling the application of our findings to diverse populations. This study also has several limitations. The Grim Reaper was not a participant in CHAMP ("living" in specific suburbs in inner western Sydney being a selection criterion). Therefore we were unable to measure his actual walking speed. Rather, we used receiver operating characteristics analysis to estimate a likely walking speed on the assumption that this would be the speed that best predicted mortality. However, as it is possible that Death's walking speed varies between work and leisure time, a clinic assessment of his walking speed without the occurrence of death in a nearby individual could inaccurately represent Death's usual pace under working conditions. Hence we do not believe this limitation to be an important one.

The receiver operating characteristics analysis was not adjusted for age, which may have resulted in different findings.

Participants' ability to outrun Death may have been also influenced by their use of performance impairing medicines, such as anticholinergic and sedative drugs that have been linked to slower walking speed in older people. ${ }^{13}{ }^{14}$ Men who were unable to complete the walking test $(n=77)$ were not included in the analysis, which limits the generalisability of our findings to men who are able to walk at least several metres. The low participation rate in CHAMP is also a limitation; however, it is similar to that of other studies of older men including a clinic visit. $^{15} 16$

A further limitation is that we were unable to collect data on the presence of resources that have been reported as enabling people to avoid Death, such as invisibility cloaks, resurrection stones, and elder wands (collectively known as the Deathly Hallows). ${ }^{3}$ Lack of foresight meant that questions on the use of magical objects were excluded from the CHAMP study questionnaire. Therefore we are unable to confirm whether slow walking speed remains an important predictor of increased mortality risk in those with access to such resources. The Grim Reaper has been reported to "bend the rules" on occasion, and famous accounts abound of people managing to trick him out of taking their life. ${ }^{17}{ }^{18}$ Future research could investigate whether a person's level of cunning, measured on a suitably developed scale such as the potential CCATBS (the Cunning, Conniving and All-round Tricky Bastard Scale), enables them to walk at slow speeds while still avoiding Death. Furthermore, as singing when feeling down is often considered like a health talisman, studies could test the possibility of using a song (see web extra) as an magical incantation to ward off Death.

\section{Conclusions and clinical implications}

This study has important implications for clinical practice and the development of future strategies for health promotion in older people. Our findings add to past research indicating a strong link between walking speed and mortality by suggesting the involvement of the Grim Reaper as an underlying mechanism for this association. Past research has suggested the use of walking speed as a tool to identify individuals at higher risk of death who may benefit from preventive interventions. The estimate of the walking speed of the Grim Reaper given in this paper is an important addition to the risk stratification function of walking speed. Interventional studies are required to assess the applicability of these findings as a motivational tool to improve participation and adherence to health promotional activities. The application of electronic tools such as $B M J \mathrm{iPad}$ to monitor the walking speed of the Grim Reaper warrants further research.

Contributors: FFS conceived, designed, and funded the study, analysed and interpreted the data, and drafted and critically revised the article. FFS, DG, FMB, DGLeC, VN, LW, MJS, DJH, PNS and RGC helped design the study, analyse and interpret the data, and critically revise the article. FFS is guarantor. All authors had full access to the data and take responsibility for its integrity and the accuracy of the analysis.

Funding: The CHAMP study is funded by the Australian National Health and Medical Research Council (grant No 301916), Sydney Medical School Foundation, and Ageing and Alzheimer's Research Foundation. The funding source had no involvement in the study design, analysis, interpretation, or decision to submit this work.

Competing interests: All authors have completed the ICMJE uniform disclosure form at www.icmje.org/coi_disclosure.pdf (available on request from the corresponding author) and declare: no support from any organisation for the submitted work; no financial relationships with any organisations that might have an interest in the submitted work in the previous three years; and no other relationships or activities that could appear to have influenced the submitted work.

Ethical approval: This study was approved by the Sydney South West Area Health Service human research ethics committee. All participants gave informed consent.

Data sharing: No additional data available.

Pratchett T. Reaper man. Corgi, 1991

Bergman I (director). Det sjunde inseglet [The seventh seal]. Svensk Filmindustri, 1957. Rowling JK. Harry Potter and the deathly hallows. Bloomsbury, 2007. Pratchett T. Mort. Corgi, 1998

5 Cesari M, Kritchevsky SB, Newman AB, Simonsick EM, Harris TB, Penninx BW, et al. Added value of physical performance measures in predicting adverse health-related events: results from the Health, Aging And Body Composition Study. J Am Geriatr Soc 2009;57:251-9.

6 Cesari M, Kritchevsky SB, Penninx BW, Nicklas BJ, Simonsick EM, Newman AB, et al. Prognostic value of usual gait speed in well-functioning older people-results from the Health, Aging and Body Composition Study. J Am Geriatr Soc 2005;53:1675-80.

7 Rosano C, Newman AB, Katz R, Hirsch CH, Kuller LH. Association between lower digit symbol substitution test score and slower gait and greater risk of mortality and of developing incident disability in well-functioning older adults. J Am Geriatr Soc 2008:56:1618-25.

8 Studenski S, Perera S, Patel K, Rosano C, Faulkner K, Inzitari M, et al. Gait speed and survival in older adults. JAMA 2011;305:50-8.

9 Cumming RG, Handelsman D, Seibel MJ, Creasey H, Sambrook P, Waite L, et al. Cohort profile: the Concord Health and Ageing in Men Project (CHAMP). Int J Epidemiol 2009;38:374-8.

10 Orwoll E, Blank JB, Barrett-Connor E, Cauley J, Cummings S, Ensrud K, et al. Design and baseline characteristics of the osteoporotic fractures in men (MrOS) study-a large observational study of the determinants of fracture in older men. Contemp Clin Trials 2005;26:569-85.

11 Fried LP, Tangen CM, Walston J, Newman AB, Hirsch C, Gottdiener J, et al. Frailty in older adults: evidence for a phenotype. J Gerontol A Biol Sci Med Sci 2001;56:M146-56.

12 Ruopp MD, Perkins NJ, Whitcomb BW, Schisterman EF. Youden index and optimal cut-point estimated from observations affected by a lower limit of detection. Biom $\mathrm{J}$ 2008;50:419-30.

13 Gnjidic D, Cumming RG, Le Couteur DG, Handelsman DJ, Naganathan V, Abernethy $\mathrm{DR}$, et al. Drug burden index and physical function in older Australian men. Br J Clin Pharmacol 2009;68:97-105

14 Gnjidic D, Bell JS, Hilmer SN, Lonnroos E, Sulkava R, Hartikainen S. Drug burden index associated with function in community dwelling older people living in Finland. Ann Med 2011; published online $15 \mathrm{Apr}$

15 Andrew SG, Cheok F, Carr S. The Australian Longitudinal Study of Ageing. Aust J Age 1989;8:31-5.

16 Nguyen T, Sambrook P, Kelly P, Jones G, Lord S, Freund J, et al. Prediction of osteoporotic fractures by postural instability and bone density. BMJ 1993;307:1111-5.

17 Pratchett T. The colour of magic. Corgi, 1985.

18 Longfellow HW. The legend of Rabbi Levi. In: The complete poetical works of Henry Wordsworth Longfellow. Houghton Mifflin, 1902:345.

Accepted: 21 November 2011

\section{Cite this as: BMJ 2011;343:d7679}

This is an open-access article distributed under the terms of the Creative Commons Attribution Non-commercial License, which permits use, distribution, and reproduction in any medium, provided the original work is properly cited, the use is non commercial and is otherwise in compliance with the license. See: $\mathrm{http}: / /$ creativecommons.org/licenses/by$\mathrm{nc} / 2.0 /$ and http://creativecommons.org/licenses/by-nc/2.0/legalcode. 


\section{What is already known on this topic}

The Grim Reaper, the personification of death, is a well known mythological and literary figure

High quality scientific research linking the Grim Reaper to mortality is limited, despite extensive anecdotal evidence attesting his important role in death

\section{What this study adds}

The Grim Reaper prefers to walk at $0.82 \mathrm{~m} / \mathrm{s}$ (2 miles (about $3 \mathrm{~km}$ ) per hour), with a maximum estimated speed of $1.36 \mathrm{~m} / \mathrm{s}$ ( $3 \mathrm{miles}$ (about $5 \mathrm{~km}$ ) per hour)

Older men wishing to outrun the Grim Reaper should maintain walking speeds above these levels

\section{Figures}

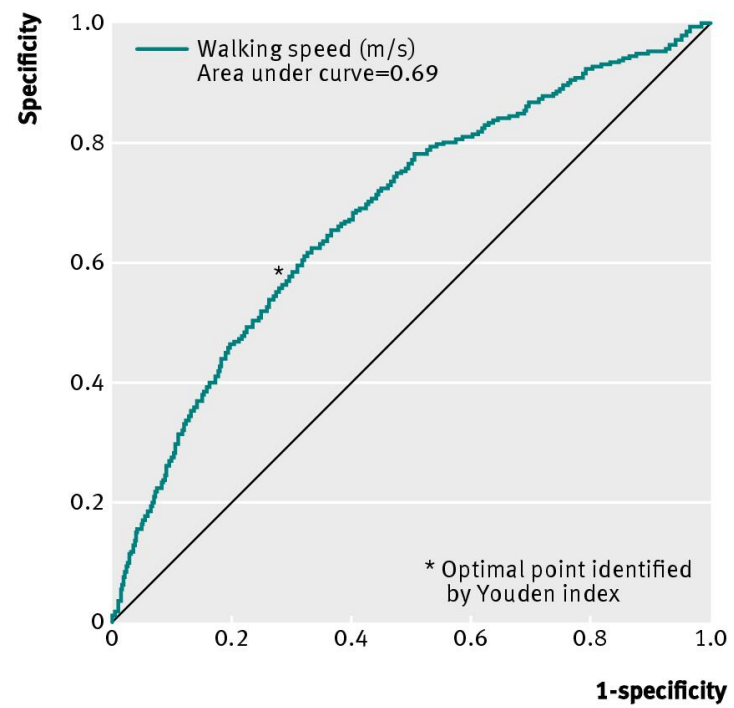

Receiver operating characteristics curve for mortality over five years in relation to walking speed. *Optimal point identified by Youden index

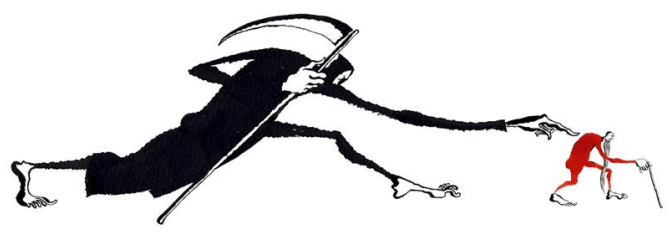

